\title{
Antonella Medici
}

\section{ZONA DE PODER.} PRODUCCIÓN ARTÍSTICA, EXCEPCIONES Y REAPROPIACIONES DEL CUERPO $^{1}$

“[... el cuerpo no es un lugar de resistencia ante un poder que existe fuera de él; dentro del cuerpo tiene lugar una tensión constante entre los mecanismos del poder y las técnicas de la resistencia." -Michel Feher ${ }^{2}$

Según Giorgio Agamben en su obra Nudità ${ }^{3}$ una de las consecuencias del actual sistema biopolítico es la perdida de nuestra "máscara", la que nos aporta un rol jurídico, un reconocimiento social y una dignidad política. Esta extracción de la máscara provoca una problemática en el momento de construir una identidad personal, puesto que si mi identidad está ahora determinada en última instancia por los datos biológicos, que no dependen de mi voluntad, la construcción de algo como una ética personal se volvería compleja. ¿Qué significa, entonces, ser reconocido si el objeto del reconocimiento no es ya una persona sino un dato numérico/ biológico/ estadístico que reduce a los individuos a la mera forma de "nuda vida", es decir, a la categoría única de "ser viviente"? En el momento en que

\footnotetext{
${ }^{1}$ Curator's Statement escrito para el seminario "On Mediation. Teoría y prácticas curatoriales en el mundo global”, organizado por el grupo de investigación Art, Globalization, Interculturality (Universitat de Barcelona).

${ }^{2}$ Jones, El cuerpo del artista, 22.

${ }^{3}$ Agamben, G. (2009). Nudità. Roma: Nottetempo.
} 
el sujeto adquiere una identidad puramente biológica y asocial, ésta le permite asumir todas las máscaras y todas las vidas posibles, ninguna de las cuales podrá nunca pertenecerle propiamente.

Esta extracción de la máscara social a la que se refiere Agamben y la subyacente aculturación de los sujetos forma parte del proceso, del que ya habla Michel Foucault en $1976,{ }^{4}$ que tiene como objetivo último la instrumentalización de la vida humana en todas sus facetas. La biopolítica es definida como "la gestión política total, o la intervención o intrusión calculada, subliminal o directa del poder-saber en todas las facetas de la vida humana",5 un sistema de poder que determina unas relaciones que en nuestras sociedades democráticas sujetan a los individuos a determinadas formas de identidad o simplemente las anulan.

Pero a pesar del despojo de la experiencia individual al que se somete el individuo en la sociedad contemporánea, existen diversos mecanismos de resistencia a esta intervención política total. Como explica Moreno Fraginals: "La clase dominante aplica al máximo sus mecanismos de deculturación como herramienta de hegemonía" mientras que "la clase dominada se refugia en su cultura como recurso de identidad y supervivencia, dado que la cultura común imparte dignidad, cohesión e identidad a un grupo humano".

Mediante este trabajo se pretende realizar un análisis abierto sobre las formas en que el sistema biopolítico actúa sobre el individuo y las múltiples estrategias y fisuras que a su vez éste produce desde el terreno artístico para resistir a su control; en palabras de Deleuze "los centros de poder se definen por lo que se les escapa y por su impotencia más que por su zona de poder". Z Zona de poder hace referencia en este ensayo, de forma subvertida, a esta geografía personal que asume al individuo no simplemente como viviente, consumidor o productor, sino como persona integral en el intento de recuperación de esta máscara social perdida,

\footnotetext{
${ }^{4}$ Foucault, M. (2002). Vigilar y Castigar. Buenos Aires: Siglo Veintiuno editores.

${ }^{5}$ Bruña Bragado, M. J. Mira Delli-Zotti, G. (2013). Ruinas del Imaginario Nacional argentino: contar Malvinas. Kamchatka, revista de análisis cultural, 1, 37-61, 38.

${ }^{6}$ Fraginals, M. M. (1983) La Historia como arma y otros estudios sobre esclavos ingenios y plantaciones. Madrid: Crítica Historia, 26.

${ }^{7}$ Deleuze, G; Guattari, F. (1988). Mil mesetas: capitalismo y esquizofrenia. Valencia: Pre-textos, 222.
} 
resistiéndose a la desaparición y reafirmándose como sujeto capaz de decisión en la lucha por la reconquista del lenguaje simbólico. Este recorrido sitúa, sin voluntad de privilegiar ningún lenguaje ni forma de producción artística, las diferentes manifestaciones que desde la colectividad o la individualidad se rebelan contra el estatus quo del sistema de poder, ya sea en su estado "normalizado" (el cual vivimos en estos momentos) o en su faceta más "excepcional” y paradigmática, como lo fueron algunas experiencias concentracionarias. Estas producciones intentan reapropiarse, simbólica o realmente, de la propia corporalidad, entendida como un archivo político y cultural, abriéndose a nuevas significaciones que combatan la reducción del cuerpo a simple estatuto biológico.

\section{Las excepciones del cuerpo}

"La excepción explica lo general y se explica a sí misma. Si se quiere estudiar correctamente lo general, es necesario ocuparse de una excepción real."

-S. Kierkegaard

El caso paradigmático del sistema biopolítico contemporáneo es, según Agamben, el campo de concentración, al que éste llama "nomos de la modernidad". Teniendo sus inicios en las estructuras concentracionarias de la Segunda Guerra Mundial, que materializaron la coyuntura de un "falso estado de excepción", sus procedimientos y tecnologías han trascendido diferentes geografías y décadas.

Algunos ejemplos de estos sistemas represivos "excepcionales" se desarrollaron durante las Dictaduras de los años 70 y 80 del Cono Sur latinoamericano. En concreto, el caso uruguayo mantuvo dentro de un marco institucionalizado un sistema represivo en el que el Estado acabó por aplicar la reclusión "penitenciaria” a seis mil trescientas personas ${ }^{10}$ desde 1970 . Además de esta cifra, de acuerdo con

\footnotetext{
${ }^{8}$ Agamben, G.. (2004). Estado de Excepción: Homo Sacer II. Valencia: Pre-textos.

${ }^{9}$ Consideramos la construcción de este sistema represivo como es el campo de concentración dentro de un contexto de "falso estado de excepción" por tratarse de un estado de excepción intencionado, que queda fuera de las necesidades de un contexto bélico de peligro exterior o de carácter provisional, lo que le lleva, como consecuencia, a confundirse con la propia norma. Agamben, G.. (1998). Homo Sacer, El poder soberano y la nuda vida: Homo Sacer I. Valencia: Pre-textos, 213-214.

${ }^{10}$ Cifra según SERPAJ (servicio de paz y justicia). Gavilán Vidal, J. (2007). "Testimonio del

Terror. Tortura y prisión en el Uruguay de la dictadura”. En E. Rey Tristán (Dir.), Memorias de la
} 
el informe final de la Comisión para la Paz, hoy en día existen 174 detenidos desaparecidos y cerca de un centenar de personas muertas en las cárceles durante esta época. La desaparición, en este contexto, fue utilizada como instrumento para producir terror y desamparo. En la mayoría de casos las desapariciones verificadas en el territorio uruguayo fueron un recurso para encubrir asesinatos (por torturas o eventuales ejecuciones) de prisioneros políticos por parte de militares y policías, pero también se usó en algunos casos, como indica Sara Méndez, como sistema concreto y programado. ${ }^{11}$

El concepto de "desaparecido" encierra muchas cuestiones que van más allá del asesinato de una persona. Como explica José María López Mazz, la desaparición "menoscaba los derechos de las víctimas y atenta contra el desenlace jurídico de la situación creada a partir de la ausencia física $\left[\ldots . .{ }^{12}{ }^{12}\right.$ Sin ningún tipo de vestigio del hecho y con un cuerpo ausente y sin rastro, los procesos legales se tornan inefectivos. Además, esta carencia material genera una herida abierta entre los familiares y amigos, que fomenta un daño permanente y traslada al colectivo social la continuidad e intemporalidad de la represión.

En el contexto post-dictatorial uruguayo situamos la performance de Clemente Padín, Punto Final (2006). ${ }^{13}$ En ella su cuerpo es a la vez site simbólico y referente de su propio "público", el cual se identifica con la corporalidad y temporalidad del artista. Mediante esta acción Padín convierte su cuerpo en un sujeto colectivo, en cuerpo social y en una potencia política que asume las individualidades desaparecidas por la dictadura. Se trata de una escena ritual y a la

violencia en Uruguay y Argentina. Golpes, dictaduras, exilios (1973-2006). Universidad de Santiago de Compostela, 113-122.

${ }^{11}$ Méndez, S. (2007). "La coordinación represiva en el Cono sur a través de sus víctimas. La desaparición forzada y el secuestro de niños”. En Rey Tristán, E. (Dir.). Memorias de la violencia en Uruguay y Argentina. Golpes, Dictaduras, exilios (1973-2006). Universidad de Santiago de Compostela, 133-151.

${ }^{12}$ López Mazz, J. M. (2006). “Un mirada arqueológica a la represión política en Uruguay (19711985)”, 150. En Funari, A.; Paulo, P.; Zarakin, A. Arqueología de la represión y la resistencia en América Latina 1960-1980. Argentina: Encuentro Grupo Editor, 147-158, 150.

${ }^{13}$ Performance realizada en el Foyer del Teatro Solís, Montevideo, Uruguay el 23 de Setiembre de 2006 en el marco del evento "Por la memoria" a cargo de los curadores Annabella Balduvino y Elbio Ferrario y organizado por el Teatro "El Galpón” y "Madres y familiares de Uruguayos detenidos desaparecidos". 
vez violenta, en la que el artista coloca en íntima relación lo público y lo privado, lo social y lo individual, la presencia y la ausencia.

Para Padín la legitimidad del arte yace en la recuperación de su función social: "que vuelva a ser legítima expresión de la sociedad que le da origen y no expresión de manejos especulativos o de "discursos ideológicos". Por tanto, promueve la obra como "instrumento de comunicación", con el objetivo de que el arte pueda llegar a recuperar "su sentido político [...], como mecanismo de recuperación de consciencia social y como instrumento de conocimiento $[. .].]^{\prime 14}$

Teniendo en cuenta algunas aportaciones del teórico Jorge Glusberg podemos tratar el cuerpo humano como una materia significante, plástica y dúctil, como una "expresión biológica de la acción cultural", ${ }^{15}$ y como tal, muy determinada por convenciones. Aquí se halla una de las particularidades de las performances y del arte corporal y es que estos "programas gestuales o comportamentales no responden, excepto ciertos casos, a las convenciones normalizadas, sino que imponen sus nuevos significados $[\ldots]{ }^{\prime} .{ }^{16}$

La performance no trabaja únicamente con el cuerpo, sino con su discurso, que está codificado, además, según convenciones contestatarias, abriendo un conflicto con lo normalizado y lo asumido. ${ }^{17}$ Esta cuestión, por otro lado, establece una complejidad en lo referente al público: dado que la performance es creadora de discursos que amplían los límites, el espectador necesita una capacidad de apertura hacia lo nuevo. El público "[...] vive la ficción de su propio cuerpo, es decir, una regulación impuesta por rituales sociales aceptados. Frente a esta ficción, los artistas oponen un cuerpo que dramatiza la realidad actuante, la caricaturiza, la enfatiza o la transgrede". ${ }^{18}$ Los lugares públicos se presentan idóneos para compartir las experiencias en las cuales el público es cuerpo social pero también actor participativo, "consumidor" de la obra y a la vez creador de

\footnotetext{
${ }^{14}$ Padín, C. (2007). 40 años de performances e intervenciones urbanas. Montevideo: Yagurú, 113.

${ }^{15}$ Glusberg, J. (1986). El Arte de la Performance. Buenos Aires: Ediciones de Arte Gaglianone, Buenos Aires, 40.

${ }^{16}$ Glusberg, El Arte de la Performance, 41.

${ }^{17}$ Glusberg, El Arte de la Performance, 41.

${ }^{18}$ Glusberg, El Arte de la Performance, 41.
} 
ésta, receptor y memoria viva de aquella coyuntura y a la vez productor de resistencia. ${ }^{19}$

Una de las cuestiones más claras y características de la performance y de las acciones de Clemente Padín es esta utilización que hace del cuerpo como una herramienta activa. No tan solo haciendo uso de éste como medio de creación que separa al artista de la obra-objeto, sino del propio cuerpo como obra, transmitiendo discursos directos con su codificación. Este uso deja en evidencia el sentido de la actividad humana y la idea de "acción-consecuencia" ${ }^{20}$ por tratarse de un arte de la "presentación" y no de la "representación". ${ }^{21}$ Como explica Henri Lefebvre "el cuerpo es el medio por el que nos materializamos como seres sociales, por el que producimos espacio social" 22 y, por tanto, Padín propone el mismo como espacio reivindicativo.

Por otro lado, Jorge Tiscornia trabaja a partir de elementos reales. Entre 1972 y 1985 estuvo preso en el Penal de Libertad, Uruguay (la mayor cárcel para presos políticos en la América Latina de los años setenta), periodo en el cual crea una serie de Almanaques en los que registra la vida cotidiana. Marcas de cuatro mil seiscientos cuarenta y seis días que eran necesarias ocultar de la represión. Este objeto tan cotidiano muestra la voluntad que se resiste a la aculturación en una situación biopolítica extrema, en donde las tecnologías del poder se infiltran hasta en el último rasgo de la persona, e intenta mantener la conexión con los referentes culturales, materializando la existencia de una identidad cultural y social arrancada.

La serie Máscaras (1985-1987) de Horacio Faedo habla a propósito de esta cosificación. El artista trata la figura de la máscara en referencia directa al elemento subyacente, ${ }^{23}$ al animal, el monstruo bajo todas las falsas máscaras posibles en la sociedad contemporánea, es decir, lo que calificaría Agamben como la "nuda vida". Una representación que hace referencia a lo que se oculta debajo

\footnotetext{
${ }^{19}$ Glusberg, El Arte de la Performance, 42.

${ }^{20}$ Bentancur, P.; Polkinhorn, H.; Young, K.; et al. (2006). Clemente Padín. Montevideo: Edición Banco central del Uruguay.

${ }^{21}$ Padín, 40 años de performances e intervenciones urbanas.

${ }^{22}$ Jones, A. (2006). El cuerpo del artista. Londres: Phaidon.

${ }^{23}$ Medici, A (2012). Entrevista con Horacio Faedo. Uruguay (inédita).
} 
del ser social, bajo la máscara tradicional, un ser reducido a un dato biológico, a la animalización, pero con la trágica consciencia del Yo.

Tal como indicaba Agamben, ¿qué se puede esperar de una humanidad en la que la máscara social, es decir, la personalidad, es tan ambigua como facetas queramos tener y tan incierta que ya el mismo concepto de humano queda desdibujado? Esta problemática que se manifiesta poéticamente en la serie máscaras no es un caso único en la producción de Faedo. Observamos también como en una de sus obras literarias "Mariposa Rea" (1986), obra que fusiona la estructura teatral y la poesía experimental y contestataria, los personajes aparecen carentes de nombres y permutables.

En origen ubicada en un marco post-dictatorial y en íntima conexión con el desgarro de los sujetos sometidos a las experiencias extremas de la tortura, las máscaras nos enlazan con el mismo punto en que el dolor producido por la tortura es tan fuerte que la única capacidad de supervivencia es el desgarro. Como explica Jaume Peris Blanes, ${ }^{24}$ la tortura separa el ser humano en dos y agudiza la distinción entre consciencia y cuerpo. El trauma del suplicio, del dolor extremo, aísla las dimensiones corporales de las subjetivas como consecuencia inherente al proceso. Sobre este cuerpo superviviente y un individuo anulado mucho más dócil, la lógica concentracionaria actúa con más facilidad para lograr una destrucción más exitosa de las identidades.

$\mathrm{Al}$ salir de uno mismo, es decir, al evadir a la persona/máscara social del cuerpo físico/“viviente” biológicamente, ¿hasta dónde llega la ruptura?, ¿hasta dónde llega el desagarro?, ¿qué es humano y qué es biológico? Pero aún más interesante sería hablar de la figura de la máscara no en referencia al receptor del dolor extremo, sino al causante de éste. ¿Y si la máscara fuera el fondo, la realidad subyacente que se oculta tras la maquinaria institucional y burocrática que invisibiliza a los productores del dolor extremo? Personas que se ubicarían en la misma Zona Gris a la que Giorgio Agamben también hace referencia respecto a los mandos de los campos nazis. Estos mismos fueron analizados en paralelo a la

${ }^{24}$ Peris Blanes, J. (2007). No queda Nada de Mi. Genealogía de la supervivencia y el testimonio de los campos de concentración chilenos (1973-2005). Universitat de Valencia: Servei de Publicacions. 
figura del musulmán por haber "[...] abdicado del margen irrenunciable de la libertad" y haber "[...] perdido en consecuencia cualquier resto de vida afectiva o de humanidad". ${ }^{25}$ Tal como relata el testimonio de Bettlheim sobre los mandos en Auschwitz: "No era un musulmán, porque estaba bien alimentado y bien vestido, pero se había despojado por completo del respeto de sí mismo y del amor propio, hasta el punto de no ser más que una máquina cuyos botones de mando eran accionados por los superiores". ${ }^{26}$

Históricamente, la brutalidad a la que se somete el cuerpo en la experiencia bélica o en el campo de concentración, inspiró y propició manifestaciones artísticas muy transgresoras como lo fue el lenguaje simbólico que desarrollaron los accionistas vieneses. Artistas que utilizaron su propio cuerpo como Günter Bruss, Herman Nitsch u Otto Mühl para realizar acciones que podrían considerarse una respuesta directa a la situación de posguerra de países como Alemania o Austria, que remiten a la barbaridad, la auto-destrucción y la decadencia de la raza humana. ${ }^{27}$

Recordando a Foucault, el poder, y más específicamente el caso de un poder altamente represivo (tanto de un estado de Excepción como de una democracia excepcional), se infiltra en el sujeto de una manera microfísica, llegando a controlar cada aspecto individual y anulando cualquier margen de libertad sobre él mismo, intentando además controlar la propia subjetividad. Pero a la vez, el poder produce por naturaleza fisuras, resistencias. "La disciplina hace crecer la habilidad de cada cual, coordina estas habilidades, acelera los movimientos, multiplica la potencia de fuego, ensancha los frentes de ataque sin disminuir su vigor, aumenta la capacidad de resistencia, etc." ${ }^{28}$ La represión produce rebelión, y en este caso el cuerpo del propio artista ha funcionado como una resistencia ante el poder.

\footnotetext{
${ }^{25}$ Agamben, G. (1999). Lo que queda de Auschwitz, El archivo y el testigo. Valencia: Pre-textos, 58.

${ }^{26}$ Agamben, G.. Lo que queda de Auschwitz, El archivo y el testigo, 307.

${ }^{27}$ Soláns, P. (2000). Accionismo vienés. Guipúzcoa: Nerea.

${ }^{28}$ Foucault, Vigilar y Castigar, 127.
} 


\title{
Reapropiaciones del cuerpo
}

\author{
"Solo dejando constancia, tratándose de aceptar ésta como realidad, como cumplimiento \\ paradójico de la promesa del desarrollo social y político de Occidente, puede plantearse la \\ auténtica resistencia desde, en expresión de Pasolini, los "resplandores supervivientes de los \\ contrapoderes." \\ -Georges Didi-Huberman
}

"Debemos regresar a la sociedad con la que estamos en contacto por el mero hecho de existir, y que llevamos con nosotros ante cualquier cosificación.”

-Maurice Merlau-Ponty

Hoy en día, debido a la crisis de valores que vive la población a nivel global, la producción artística, los lenguajes, las estéticas y en la propia ontología del arte se han visto también cuestionadas. En los últimos años, el arte ha asumido un papel activo y determinante como estrategia de re-apropiación, tanto de los espacios y del lenguaje, como del propio cuerpo. Se trata de movimientos compuestos por múltiples individuos, por caras sin nombre. En muchos casos representados por el símbolo de la máscara, del cual tendríamos un claro precedente en la iconografía utilizada por el Ejercito Zapatista de liberación Nacional (EZLN), movimiento político con una estructura militar de guerrilla, cuyos integrantes se cubren con pañuelos o pasamontañas. Movimientos que al igual que el EZLN se organizan de modo anónimo y horizontal, desarrollando acciones que se transmiten viralmente y a gran velocidad, y que buscan su propia afirmación mediante la recuperación de los contextos y los medios de los que el poder se ha apropiado ilegítimamente. Grupos autónomos como a.f.r.i.k.a, Blisset o Brünzels que utilizan un lenguaje apelativo y visualmente sugerente en el que abunda el humor y la ironía para apropiarse de los medios y de las geografías cotidianas. Estas agrupaciones se caracterizan además por la voluntad de posibilitar la identificación de todas las diversas individualidades bajo un mismo rostro, mediante el que reclaman la representatividad del verdadero sujeto político. ${ }^{29}$

Mujeres Creando, descrito como Movimiento social anarco-feminista, formado horizontalmente, se ha convertido en un fenómeno político-cultural tanto en Bolivia como a nivel internacional. Buscando la directa integración de la vida

\footnotetext{
${ }^{29}$ González Marí, X. (2013). Injertarse en la Historia. Gesto creativo y estrategias de reapropiación en el activismo global. Kamchatka, Revista de análisis cultural, 1, 87-111.
} 
privada y la vida política, toman el ritual doméstico como primer objeto de cambio y lo trasladan a nivel comunitario mediante intervenciones sociales que intentan re-definir las relaciones de poder. Esta intencionalidad se puede ver, por ejemplo, en intervenciones como Seminario: Bolivia Estado Proxeneta o Intervención por el Día de la Madre. En este caso, una de las ideas del movimiento es huir de la apropiación de aquellos conceptos clave por parte del Estado como por ejemplo el concepto de "desptriarcalización". ${ }^{30}$ Se trata de un grupo horizontal pero no homogeneizado, ya que consideran fundamental la pluralidad de las identidades de las mujeres y sus realidades, evitando siempre agrupar el conjunto bajo un rostro e identidad únicos de "una mujer", en este caso boliviana.

En contraste con las formas que adopta el activismo creativo globalizado, en el que el medio para visibilizar sus reclamos (salvo algunas excepciones) esta simbólicamente basado en la difuminación de la identidades y la homogeneización de la "máscara" como recurso, ubicamos la obra de Leonora de Barros. Esta artista trabaja con la vida en su faceta más metafórica y la ubica entre la existencia y la desaparición. En su video-performance Tato de Olho (2005) se contemplan distintos planos de lectura relativos a la situación de la mujer en la sociedad actual y, sobre todo, en relación a la mujer consigo misma. De Barros visibiliza la "nudità" del individuo que se podría leer desde la perspectiva de la autodestrucción, relacionada con la autodestrucción que imponen a la mujer los modelos imposibles de las sociedades desarrolladas. Esta imposición, como señala Foucault, se realiza por parte del poder mediante la producción de "efectos positivos a nivel de deseo", y no únicamente mediante la represión, la censura o la imposición directa; es aquí donde yace su fortaleza. ${ }^{31}$ En la obra el mismo cuerpo, víctima del poder biopolítico que lo domina, se hace a la vez responsable de su propia resistencia asumiéndose mediante esta auto-reflexibilidad como su propia zona de poder.

Estas dos maneras de posicionarse frente al control total de nuestras formas de vida más básicas, es decir, de nuestra propia naturaleza humana, comprenden dos formas de representatividad y, por tanto, de resistencia en las que además se

\footnotetext{
${ }^{30}$ http://www.mujerescreando.org/

${ }^{31}$ Foucault, M. (1979). Microfísica del poder. Madrid: La Piqueta, 107.
} 
percibe una diferencia sustancial a la hora de asumir el rol de sujeto político. La propia cuestión de utilizar el cuerpo como lenguaje, independientemente de los códigos establecidos, transgrediendo los límites entre lo público y lo privado y difuminando las determinaciones interpretativas, es una resistencia. Un cuerpo que se revela, en este sentido, por ser el mismo objeto de la articulación de los poderes públicos y privados. Genera consecuentemente una autonomía mediante la cual se construye como lugar de protesta y de resistencia a la lógica represiva y hace visible la propia tensión entre estas dos fuerzas. 


\section{Bibliografía:}

Agamben, G. (1998). Homo Sacer, El poder soberano y la nuda vida: Homo Sacer I. Valencia: Pre-textos.

Agamben, G.. (2004). Estado de Excepción: Homo Sacer II. Valencia: Pre-textos

Agamben, G. (2009). Lo que queda de Auschwitz: Homo Sacer III. Valencia: Pre-textos.

Agamben, G. (2009). Nudità. Roma: Nottetempo.

Agamben, G. (2005). Profanaciones. Barcelona: Anagrama.

Bentancur, P; Polkinhorn, H; Young, K; et al. (2006). Clemente Padín. Montevideo: Edición Banco central del Uruguay.

Bruña Bragado, M. J; Mira Delli-Zotti, G. (2013). "Ruinas del Imaginario Nacional argentino: contar Malvinas”. Kamchatka, revista de análisis cultural, 1, $37-61$.

Deleuze, G; Gutarri, F. (1988). Mil mesetas: capitalismo y esquizofrenia. Valencia: Pre-textos, 222.

Gavilán Vidal, J. (2007). “Testimonio del Terror. Tortura y prisión en el Uruguay de la dictadura”. En E. Rey Tristán (dir.), Memorias de la violencia en Uruguay y Argentina. Golpes, dictaduras, exilios (1973-2006). Universidad de Santiago de Compostela, 113-122.

Glusberg, J. (1986). El Arte de la Performance. Buenos Aires: Ediciones de Arte Gaglianone.

González Marí, Ximo. (2013). Injertarse en la Historia. "Gesto creativo y estrategias de reapropiación en el activismo global”. Kamchatka, Revista de análisis cultural, 1, 87-111.

http://www.mujerescreando.org/ 
Fraginals, M. M. (1983). “Aportes culturales y deculturación”. En La Historia como arma y otros estudios sobre esclavos ingenios y plantaciones. Madrid: Crítica Historia.

Foucault, M. (1979). Microfísica del poder. Madrid: La Piqueta.

Foucault, M. (2002). Vigilar y Castigar. Buenos Aires: Siglo Veintiuno editores.

Medici, A. (Enero 2012). Entrevista con Horacio Faedo. Uruguay (inédita).

Medici, A; Masotta, G. (2012). Primer catálogo de obras escultóricas de Horacio Napoleón Faedo Salle. Montevideo: Registro de la Biblioteca Nacional del Uruguay, Tomo I.

Padín, C. (2007). 40 años de performances e intervenciones urbanas. Montevideo: Yagurú.

Peris Blanes, J. (2007). No queda Nada de Mí. Genealogía de la supervivencia y el testimonio de los campos de concentración chilenos (1973-2005). Universitat de Valencia: Servei de Publicacions.

Soláns, P. Accionismo vienés. (2000) Guipúzcoa: Nerea. 